\title{
Selection of Early Maturing and High Yielding Mutants of Toraja Local Red Rice Grown from M2-M3 Population after Ion Beam Irradiation
}

\author{
Rinaldi Sjahril ${ }^{*}$, Trisnawaty A. R², Muhammad Riadi', Rafiuddin', Tadashi Sato ${ }^{3,4}$, Kinya Toriyama ${ }^{3}$, Yoriko Hayashi", \\ Tomoko $\mathrm{Abe}^{4}$ \\ ${ }^{1}$ Department of Agronomy, Faculty of Agriculture, Hasanuddin University, Makassar, Indonesia \\ ${ }^{2}$ Department of Agrotechnology, Faculty of Science and Technology, Muhammadiyah University Sidenreng Rappang, Sidrap, \\ Indonesia \\ ${ }^{3}$ Graduate School of Agricultural Science, Tohoku University, Sendai, Japan \\ ${ }^{4}$ Ion Beam Breeding Team, RIKEN Nishina Center for Accelerator-Based Science, Wako-shi, Saitama, Japan
}

\section{ARTICLE INFO}

\section{Article history:}

Received March 14, 2019

Received in revised form February 16, 2020

Accepted February 27, 2020

KEYWORDS:

Red rice,

Toraja local rice,

mutants,

early maturity,

ion beam,

irradiation

\begin{abstract}
This study aims to obtain the genotype of local Toraja red rice mutants that have the potential to be developed into early maturing varieties and have high yields. Research carried out with a mass selection method consisting of two irradiation treatments, namely: (1) irradiation with a Carbon ion dose of 150 Gy (PL-C); (2) irradiation with Argon ion dose of $10 \mathrm{~Gy}$ (PL-A) and control as a comparison. Selected lines of M2 seed population were planted in experimental rows plus 2 rows as control, each row had 50 plants. Selection is done in two stages. The first stage, the selection was based on the criteria of plant growth components; to select rice plants that have early mid-early maturity characters, dwarf to semi-dwarf, and larger number of tillers. The second stage, selected lines from the scoring method were then grouped based on the degree of similarity with the cluster analysis method. Irradiation with ion beams produced mutants with shorter harvesting age than their. This study produced 10 selected lines, 5 lines of Carbon ion and 5 lines of Argon ion irradiation treatment, and formed 5 groups with a $90 \%$ similarity coefficient.
\end{abstract}

\section{Introduction}

Based on data from the North Toraja Regency Agriculture Service (2013), Tana Toraja is one of the areas in South Sulawesi that has a diversity of local rice germplasm. Survey of local rice in Tana Toraja Regency conducted by Sahardi and Djufry (2013) reported that there were about 29 local Toraja rice varieties, each of which had exotic characteristics such as black, red, aromatic, and fluffier rice found in that regency alone. However according to Riadi et al. (2019) there are about a total of 27 local Toraja varieties found in Tana Toraja Regency and 22 local varieties found in North Toraja Regency.

One of the local rice varieties used for generations as part of the tradition and culture of the Toraja community is red rice which in the local language is called Pare Lea.

\footnotetext{
* Corresponding Author

E-mail Address: rinaldi.sjahril@gmail.com
}

The use of local rice, especially red rice in traditional cultural rituals, helps to preserve this traditional rice variety amid the rapid use of introduced varieties.

Local rice, in general, has several disadvantages including long life, high plant posture and low yield (Wahdah et al. 2012). This character is a limiting factor that can cause farmers' interest in growing local rice to be lower, so it is feared that it will cause a lack of availability of local rice cultivars as a source of germplasm.

To optimize the potential of local rice as one of the germplasm sources for plant breeding, the first step that needs to be implemented is to improve the character of the local rice varieties. Character improvement can be done in various ways, both conventionally and mutation induction. As time goes on, breeding techniques are now being developed using ion beams through the use of heavy-ion beams. This ion beam irradiation is safer, does not damage the endosperm, because the dosage is low so the level of mutation induction is higher. 
Compared to gamma rays, ion beam irradiation has several advantages including higher mutation rates, lower doses with high survival rates, high levels of mutation induction and various other variations, ion files can be focused and regulated through the embryo tissue, and does not damage the endosperm (Yazid and Muryono 2000; Abe et al. 2012). Thus, mutation induction in local rice with radiation irradiation is expected to produce mutant rice that has properties that are better than the original varieties.

This research is expected to be the initial stage to create new red rice varieties early maturing, short postures, and high production. Based on these matters, it is necessary to carry out research "Early maturing Toraja Local Red Rice Mutant Selection from M2 Population from Ion Beam Irradiation".

\section{Materials and Methods}

\subsection{Place and Time}

This research was conducted in Alla Subdistrict, Enrekang Regency, South Sulawesi with an altitude of $650 \mathrm{~m}$ above sea level at coordinates S: $3^{\circ} 19^{\prime} 47.44 "$; E: $119^{\circ} 50^{\prime} 1.57 "$ and lasted from May to October 2017.

\subsection{Materials}

The material used was the M2 generation of local Toraja red rice (Pare Lea) seed produced by ion beam irradiation (Sjahril et al. 2018). Toraja local red rice seed (M0) was irradiated using $150 \mathrm{~Gy}$ Carbon ion beam and $10 \mathrm{~Gy}$ Argon ion beam, then grown on agricultural land in accordance with the standard of maintenance of rice plants. Individual M1 plants grew then produced seeds (M2) which were collected to be used in this study. Other materials used were manure and soil for seeding media, rat poisons, pesticides, irrigation water, and paper label. The tools used ware plastic pots for sowing, machetes, hoes, tractors, sprayers, nets, meters, analytical scales, Contador seed counter, cameras, and writing instruments.

\subsection{Methods}

This study consisted of three treatments, namely irradiation with a dose of 150 Gy Carbon ion beam (PL-C), irradiation with Argon ion dose $10 \mathrm{~Gy}$ (PL-A), and control as a comparison. M2 seeds used are seeds produced by M1 plants which produce more than 50 seeds per hill of plants. Based on these criteria there are 61 selected lines, consisting of 46 lines derived from irradiation Carbon iom beam treatment and
15 lines of Argon ion beam irradiation treatment. M2 seeds from selected lines ware planted in rows containing 50 plants each. Thus the total seeds planted from the Carbon iom beam irradiation were 2,300 seeds, and 750 seeds from Argon ion beam irradiation treatment. As a control, non-irradiated local Toraja red rice were planted in rows, each containing 50 plants. Each individual plant was given a line number that shows the row and position of the plants in the rows. The total number of individual plants grown ware 1,303 plants from the Carbon ion beam irradiation, 108 from the Argon ion beam irradiation and 89 plants from control treatment.

\subsection{Data Analysis}

Observation data in the form of plant height, harvest age and number of productive tillers counted as panicle numbers are grouped into 3 criteria classes based on the Rice Plant Characterization and Evaluation System Guide (BPPP 2003), namely:

1. Parameters of plant height: $\operatorname{dwarf}(<110 \mathrm{~cm})$, semi-dwarf $(110-130 \mathrm{~cm})$, and high $(>130$ $\mathrm{cm})$.

2. Harvesting age parameters: early ( $<120$ days), middle (120-150 days), and deep ( $>150$ days). Harvesting age is defined here as additional days of flowering growth of average 30 days from heading.

3. Parameters for the number of productive tillers: few ( $<8$ panicles), middle (9-16 panicles), and many ( $\geq 17$ panicles).

Furthermore, selection was carried out to select rice plants that had early-maturity characters, shortmedium canopy, and many tillers. Mutant frequency was calculated based on the number of mutants that have a certain character and the overall mutant plant population with the formula:

Mutant frequency (MF) $=\frac{\text { Number of mutant plants }}{\text { Number of population }} \times 100 \%$

For the selection of mutant lines based on the component production parameters, the scoring method was used. Each observation parameter from the production component was given a score, and then summed to obtain the level of association. The final result of the scoring system was the classification of the level of relevance of the output parameters calculated by the equation: 


$$
S_{n}=\left(X_{n}-X_{1}\right) / S D+S_{1}
$$

Informations:

$\mathrm{S}_{\mathrm{n}} \quad$ : data nth score

$\mathrm{SD} \quad$ : standard Deviation

$\mathrm{S}_{1} \quad$ : lowest data score

$\mathrm{X}_{\mathrm{n}} \quad$ : value of the nth data

$\mathrm{X}_{1} \quad$ : lowest data value

\section{Results}

\subsection{Number and Frequency of Mutants}

Data on plant height $(\mathrm{cm})$, harvesting age (days), and number of productive tillers (panicle) are classified into three grouping criteria. The recapitulation of the number of individuals and the frequency of mutants based on the grouping criteria is presented in Table 1.

The data in Table 1 shows irradiation treatment, both by using Carbon ions and Argon ions to improve plant height character, by producing mutants that have dwarf and semi-dwarf plant postures, even in low frequencies. The irradiation treatment of Carbon ions produced 9 plants mutant that had the character of dwarf plant postures with a frequency of $0.7 \%$ and 23 plants mutant of semi-dwarf plant postures with a frequency of $1.8 \%$. While the Argon ion irradiation treatment only produces only one plant that has the character of dwarf plant postures with a frequency of $0.9 \%$. In the Argon ion irradiation treatment was none obtained with semi-dwarf plant posture. Whereas, in the control treatment, all plant populations have high postures. Growth in the field is shown in Figure 1. Figure
1 shows field planting condition of M2 normal plants, dwarf, and semi dwarf plants.

The ion beam irradiation treatment also succeeded in producing M2-M3 mutants with a mid-early maturity harvesting age (147-148 days) than the control treatment (deep maturity, 162-165 days). In average we obtained 16-17 days earlier harvesting age (data not shown). Carbon ion irradiation treatment produced 113 mutants plants with mid-early maturing harvesting age mutant (120150 days) with a mutant frequency of $8.7 \%$. Meanwhile, Argon ion irradiation produces 23 plants middle maturing mutant (120-150 days) with a frequency of $21.3 \%$. While in control treatment, all plant populations were in the deep maturing ( $>150$ days).

The highest number of productive tillers $(\geq 17$ panicles per hill) per line was found in the treatment of irradiation with Carbon ion beam (i.e. 384 hills) with a frequency of 29.5\%, while the treatment of Argon ion irradiation reached 98 hills with a frequency of $90.7 \%$. In the control treatment, the number of hills with many productive tillers characters reached 37 plants with a frequency of $41.6 \%$.

\subsection{Lines Selection Based on Growth Components}

Based on the grouping of growth components that have been done previously, in terms of plant height, harvesting age and number of productive tillers, a combination of the three criteria is then carried out. From the results of the third combination, these components, 27 types of criteria were obtained from each treatment and the number of lines included in the criteria. The combination results obtained are presented in Table 2.

Table 1. Recapitulation of the number of individuals and mutant frequencies based on plant height (cm), harvesting age (days), and the number of productive tillers (panicles)

\begin{tabular}{|c|c|c|c|c|c|c|c|}
\hline \multirow{3}{*}{ Character } & \multirow{3}{*}{ Criteria } & \multicolumn{6}{|c|}{ Treatments ${ }^{*}$} \\
\hline & & \multicolumn{2}{|c|}{ PL-control } & \multicolumn{2}{|c|}{ PL-Carbon } & \multicolumn{2}{|c|}{ PL-Argon } \\
\hline & & $\begin{array}{l}\text { Number of } \\
\text { plants }\end{array}$ & $\begin{array}{l}\text { Frequency } \\
(\%)\end{array}$ & $\begin{array}{l}\text { Number of } \\
\text { plants }\end{array}$ & $\begin{array}{l}\text { Frequency } \\
(\%)\end{array}$ & $\begin{array}{l}\text { Number of } \\
\text { plants }\end{array}$ & $\begin{array}{l}\text { Frequency } \\
(\%)\end{array}$ \\
\hline \multirow[b]{3}{*}{ Plant height } & Dwarf $(<110 \mathrm{~cm})$ & 0 & 0.0 & 9 & 0.7 & 1 & 0.9 \\
\hline & $\begin{array}{l}\text { Semi-dwarf } \\
\quad(110-130 \mathrm{~cm})\end{array}$ & 0 & 0.0 & 23 & 1.8 & 0 & 0.0 \\
\hline & High $(>130 \mathrm{~cm})$ & 89 & 100.0 & 1,271 & 97.5 & 107 & 99.1 \\
\hline \multirow{3}{*}{$\begin{array}{l}\text { Harvesting } \\
\text { age }\end{array}$} & Early (<120 days) & 0 & 0.0 & 0 & 0.0 & 0 & 0.0 \\
\hline & $\begin{array}{l}\text { Middle (120-150 } \\
\text { days) }\end{array}$ & 0 & 0.0 & 113 & 8.7 & 23 & 21.3 \\
\hline & $\begin{array}{l}\text { Deep }(>150 \\
\text { days })\end{array}$ & 89 & 100.0 & 1,190 & 91.3 & 85 & 78.7 \\
\hline \multirow{3}{*}{$\begin{array}{l}\text { Number of } \\
\text { productive } \\
\text { tillers per } \\
\text { hill }\end{array}$} & Few $(\leq 8$ panicles $)$ & 27 & 30.3 & 340 & 26.1 & 3 & 2.8 \\
\hline & $\begin{array}{l}\text { Middle (9-16 } \\
\text { panicles) }\end{array}$ & 25 & 28.1 & 579 & 44.4 & 7 & 6.5 \\
\hline & $\begin{array}{c}\text { Many }(\geq 17 \\
\text { panicles })\end{array}$ & 37 & 41.6 & 384 & 29.5 & 98 & 90.7 \\
\hline \multicolumn{2}{|c|}{ Total number of plants } & 89 & & 1,303 & & 108 & \\
\hline
\end{tabular}




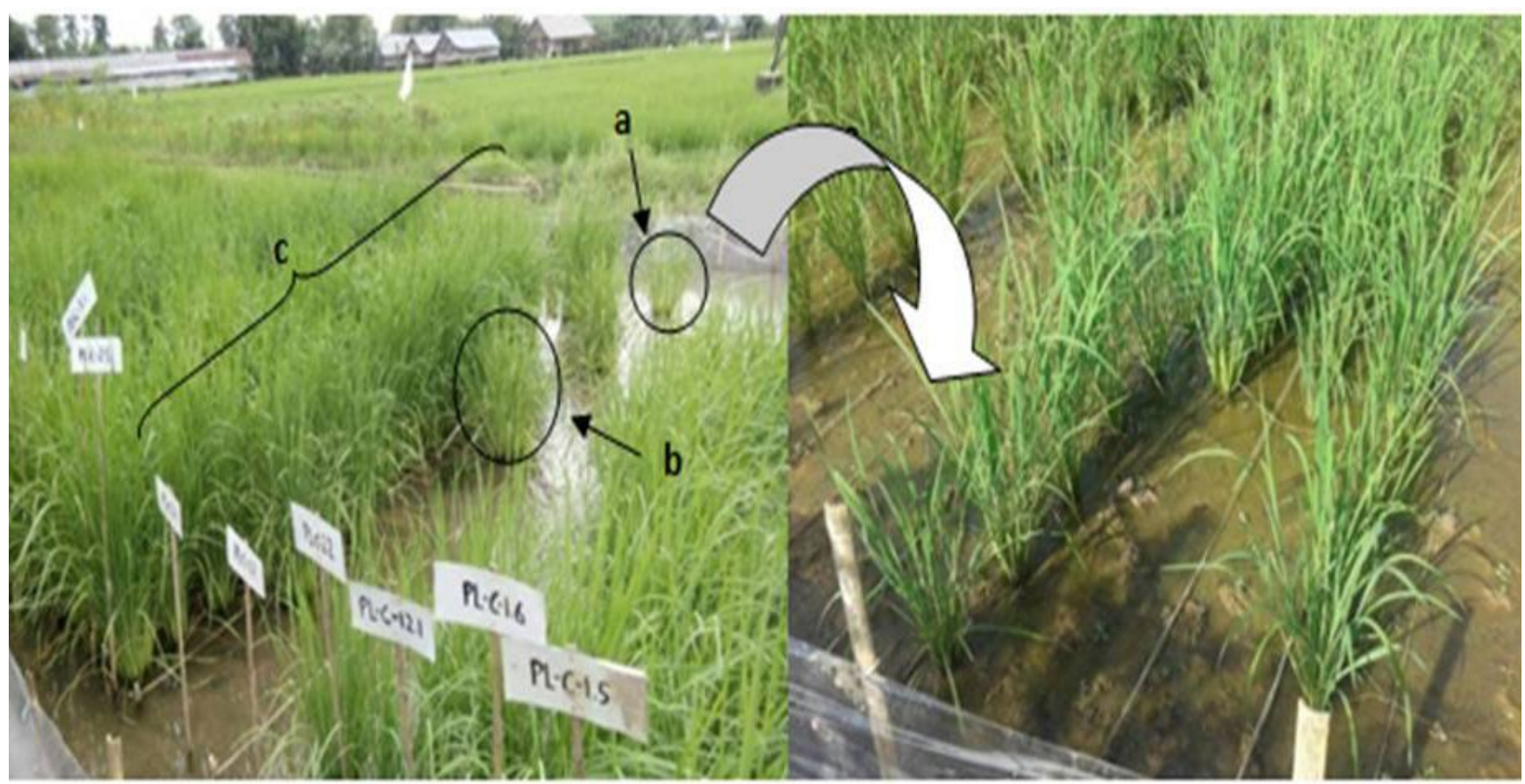

Figure 1. Variations of rice plant phenotypes at 40 days after planting (a) dwarf-type, (b) semi-dwarf type, (c) normal type

Table 2. Recapitulation of population numbers by a combination of qualitative criteria of harvesting age, plant height and number of productive tillers (panicles)

\begin{tabular}{|c|c|c|c|c|c|}
\hline \multicolumn{3}{|c|}{ Criteria } & \multicolumn{3}{|c|}{ Treatments } \\
\hline Harvesting age* & Plant height & Productive tillers & PL-control & PL-Carbon & PL-Argon \\
\hline Early & Dwarf & Few & 0 & 0 & 0 \\
\hline Early & Dwarf & Middle & 0 & 0 & 0 \\
\hline Early & Dwarf & Many & 0 & 0 & 0 \\
\hline Early & Semi-Dwarf & Few & 0 & 0 & 0 \\
\hline Early & Semi-Dwarf & Middle & 0 & 0 & 0 \\
\hline Early & Semi-Dwarf & Many & 0 & 0 & 0 \\
\hline Early & High & Few & 0 & 0 & 0 \\
\hline Early & High & Middle & 0 & 0 & 0 \\
\hline Early & High & Many & 0 & 0 & 0 \\
\hline Mid-early & Dwarf & Few & 0 & 0 & 0 \\
\hline Mid-early & Dwarf & Middle & 0 & 0 & 0 \\
\hline Mid-early & Dwarf & Many & 0 & 0 & 0 \\
\hline Mid-early & Semi-Dwarf & Few & 0 & 1 & 0 \\
\hline Mid-early & Semi-Dwarf & Middle & 0 & 0 & 0 \\
\hline Mid-early & Semi-Dwarf & Many & 0 & 0 & 0 \\
\hline Mid-early & High & Few & 0 & 31 & 1 \\
\hline Mid-early & High & Middle & 0 & 53 & 1 \\
\hline Mid-early** & High $^{* *}$ & Many** & 0 & 27 & 21 \\
\hline Deep & Dwarf & Few & 0 & 8 & 0 \\
\hline Deep & Dwarf & Middle & 0 & 1 & 0 \\
\hline Deep & Dwarf & Many & 0 & 0 & 1 \\
\hline Deep & Semi-Dwarf & Few & 0 & 14 & 0 \\
\hline Deep & Semi-Dwarf & Middle & 0 & 7 & 0 \\
\hline Deep & Semi-Dwarf & Many & 0 & 0 & 0 \\
\hline Deep & High & Few & 31 & 360 & 2 \\
\hline Deep & High & Middle & 21 & 445 & 6 \\
\hline Deep & High & Many & 37 & 356 & 76 \\
\hline Total number of & & & 89 & 1,303 & 108 \\
\hline
\end{tabular}

*Early maturity (146-153 days), Mid-early maturity (154-161 days), Deep maturity (162-168 days)

${ }^{* *}$ Criteria of the selected line 
Table 2 shows that there are no lines that meet the criteria for early maturing, dwarf postures and many tillers numbers, so that the criteria used to select are criteria for middle maturing, high posture, and many tillers. Based on these criteria, 27 plants were selected from the irradiation treatment of Carbon ion beam and 21 plants from Argon ion beam irradiation treatment. A total of 48 plants were selected.

\subsection{Lines Selection Based on Yield Components}

Based on the table of recapitulation of the number of selected lines in terms of growth components (plant height, harvesting age, and productive tillers) in Table 2, the production component data is then calculated. From the results of these calculations, the lines are grouped according to the criteria of production components that have been predetermined. The results of the calculation and grouping are then scored in the highest order. The results of the selection and scoring of selected lines based on production component data can be seen in Table 3.
From the results of the scoring, some lines have a total score above the best value limit of 37.97 were selected. The best value limit is obtained from the average value of the total score plus the standard deviation value. There were 10 lines that had a score above the best value, each of which 5 lines were from Carbon ion irradiation treatment and 5 lines were from the Argon ion irradiation treatment for selection criteria, middle maturing, high posture, and many productive tillers. The 10 lines are then grouped according to the level of similarity with the cluster analysis method. The level of similarity of these lines based on the production, components are presented in Figure 2.

Figure 2 shows that based on the dendrogram of 10 Toraja local red rice lines selected at the $90 \%$ similarity coefficient formed five groups. Group I consisted of 1 line, Group II consisted of 2 subgroups (3 lines), Group III of 1 line, Group IV of 2 lines, and Group V of 2 subgroups ( 3 lines). The group analysis of the production components based on the dendrogram graph is presented in Table 4.

Table 3. Selection and scoring results of selected lines based on growth and yield components data on Carbon and Argon ion irradiation treatments

\begin{tabular}{|c|c|c|c|c|c|c|c|c|c|c|c|c|}
\hline Nomor galur & $\mathrm{PH}$ & HD & NP & LP & NSP & WSP & $\overline{D S}$ & WFP & W100 & PBBM & PF & Total score \\
\hline PL-C-1.7-20 & 4.48 & 2.22 & 2.01 & 1.68 & 1.59 & 1.89 & 1.91 & 2.55 & 6.03 & 4.01 & 2.41 & 30.78 \\
\hline PL-C-1.7-36 & 4.23 & 2.82 & 1.80 & 1.80 & 2.08 & 2.57 & 2.58 & 3.27 & 6.24 & 4.77 & 2.87 & 35.02 \\
\hline PL-C-2.2-29 & 3.80 & 1.00 & 2.11 & 4.58 & 2.69 & 2.34 & 2.04 & 2.82 & 4.59 & 3.89 & 2.76 & 32.62 \\
\hline PL-C-3.12-10 & 2.95 & 2.22 & 1.60 & 2.46 & 1.95 & 1.36 & 2.05 & 1.78 & 5.41 & 2.31 & 1.58 & 25.66 \\
\hline PL-C-3.12-25 & 5.08 & 2.22 & 1.60 & 2.10 & 1.25 & 1.29 & 1.20 & 1.84 & 4.80 & 3.24 & 1.56 & 26.17 \\
\hline PL-C-3.12-39 & 3.55 & 2.22 & 1.60 & 1.58 & 2.87 & 2.77 & 3.94 & 3.27 & 4.70 & 4.15 & 3.08 & 33.73 \\
\hline PL-C-4.1-17* & 4.23 & 2.22 & 1.50 & 3.23 & 3.39 & 4.18 & 3.57 & 4.86 & 5.79 & 5.40 & 3.61 & 41.97 \\
\hline PL-C-9.1-8 & 4.23 & 2.22 & 1.80 & 1.77 & 2.43 & 2.69 & 3.13 & 3.07 & 6.56 & 3.78 & 2.34 & 34.01 \\
\hline PL-C-10.16-14 & 3.80 & 1.00 & 1.30 & 2.47 & 3.22 & 3.35 & 3.82 & 3.89 & 4.78 & 4.58 & 2.75 & 34.98 \\
\hline PL-C-17.9-11 & 3.12 & 1.00 & 1.00 & 3.86 & 4.06 & 3.65 & 4.04 & 4.23 & 3.52 & 4.86 & 2.61 & 35.95 \\
\hline PL-C-17.13-2 & 2.95 & 1.00 & 2.31 & 1.17 & 1.55 & 2.07 & 2.12 & 2.87 & 5.85 & 4.87 & 2.66 & 29.40 \\
\hline PL-C-17.13-4 & 3.46 & 1.00 & 1.00 & 1.75 & 1.75 & 2.06 & 2.12 & 2.59 & 5.94 & 3.63 & 1.57 & 26.88 \\
\hline PL-C-17.13-21 & 4.23 & 2.22 & 1.30 & 1.17 & 1.63 & 1.80 & 2.25 & 2.23 & 5.23 & 3.35 & 1.75 & 27.15 \\
\hline PL-C-17.13-43 & 2.53 & 1.00 & 1.40 & 1.16 & 1.58 & 1.87 & 2.18 & 2.53 & 5.38 & 4.21 & 1.73 & 25.58 \\
\hline PL-C-18.2-1 & 3.55 & 1.00 & 2.01 & 3.16 & 3.62 & 2.15 & 3.92 & 2.49 & 3.45 & 1.88 & 2.35 & 29.58 \\
\hline PL-C-18.2-20 & 1.68 & 1.00 & 1.20 & 3.06 & 3.08 & 2.80 & 3.26 & 3.25 & 5.75 & 3.73 & 2.28 & 31.09 \\
\hline PL-C-18.8-22 & 3.97 & 1.00 & 1.00 & 2.00 & 2.13 & 2.47 & 2.55 & 2.99 & 5.76 & 3.94 & 1.97 & 29.78 \\
\hline PL-C-18.8-40 & 4.23 & 1.00 & 2.01 & 1.52 & 1.62 & 2.11 & 2.04 & 2.77 & 5.12 & 4.64 & 2.36 & 29.41 \\
\hline PL-C-19.4-21 & 1.00 & 1.00 & 1.00 & 4.35 & 3.80 & 2.85 & 3.45 & 3.08 & 4.68 & 3.09 & 2.02 & 30.33 \\
\hline PL-C-19.10-43 & 4.48 & 2.82 & 2.61 & 1.02 & 1.71 & 2.22 & 2.46 & 2.93 & 5.48 & 4.64 & 3.17 & 33.55 \\
\hline PL-C-20.1-1* & 3.89 & 1.00 & 1.80 & 3.50 & 3.50 & 4.17 & 3.55 & 5.02 & 5.55 & 5.61 & 4.14 & 41.74 \\
\hline PL-C-20.5-44* & 2.78 & 1.00 & 1.00 & 3.42 & 4.01 & 4.44 & 4.25 & 5.10 & 6.01 & 4.82 & 3.06 & 39.88 \\
\hline PL-C-20.5-49* & 3.80 & 1.00 & 1.20 & 3.34 & 2.88 & 3.99 & 2.85 & 4.96 & 5.98 & 6.04 & 3.27 & 39.32 \\
\hline PL-C-20.6-6 & 2.02 & 1.00 & 1.40 & 1.36 & 1.51 & 2.26 & 1.95 & 3.08 & 5.72 & 5.28 & 2.34 & 27.92 \\
\hline PL-C-20.6-7 & 1.85 & 1.00 & 1.20 & 1.48 & 1.61 & 2.48 & 2.04 & 3.29 & 7.11 & 5.16 & 2.22 & 29.44 \\
\hline PL-C-20.6-50 & 5.08 & 1.00 & 1.70 & 1.14 & 1.73 & 2.35 & 2.44 & 3.09 & 5.64 & 4.83 & 2.60 & 31.60 \\
\hline PL-C-20.11-44* & 2.10 & 1.00 & 1.20 & 3.90 & 4.83 & 4.59 & 4.96 & 4.92 & 5.37 & 4.11 & 3.24 & 40.23 \\
\hline PL-A-1.1-8 & 2.36 & 1.00 & 1.30 & 2.75 & 1.40 & 1.15 & 1.15 & 1.60 & 3.59 & 2.59 & 1.36 & 20.25 \\
\hline
\end{tabular}


Table 3. Continued

\begin{tabular}{|c|c|c|c|c|c|c|c|c|c|c|c|c|}
\hline Nomor galur & $\mathrm{PH}$ & $\mathrm{HD}$ & NP & LP & NSP & WSP & DS & WFP & W100 & PBBM & $\mathrm{PF}$ & Total score \\
\hline PL-A-1.1-12 & 3.21 & 1.00 & 1.60 & 3.45 & 2.83 & 1.00 & 2.73 & 1.00 & 1.00 & 1.00 & 1.00 & 19.82 \\
\hline PL-A-1.1-20 & 2.10 & 1.00 & 1.60 & 1.69 & 1.00 & 1.44 & 1.00 & 2.24 & 5.23 & 4.83 & 1.86 & 23.99 \\
\hline PL-A-1.1-21 & 1.59 & 1.00 & 2.01 & 2.52 & 1.50 & 1.87 & 1.39 & 2.62 & 4.92 & 4.79 & 2.45 & 26.67 \\
\hline PL-A-1.1-22 & 2.10 & 1.00 & 1.60 & 1.72 & 1.02 & 1.15 & 1.01 & 1.93 & 5.36 & 4.58 & 1.57 & 23.04 \\
\hline PL-A-1.1-24 & 2.02 & 1.00 & 2.41 & 2.97 & 2.32 & 2.61 & 2.30 & 3.29 & 5.02 & 4.63 & 3.27 & 31.83 \\
\hline PL-A-1.1-35 & 4.14 & 1.00 & 1.91 & 2.44 & 1.85 & 1.70 & 1.91 & 2.21 & 4.30 & 3.42 & 2.07 & 26.95 \\
\hline PL-A-1.1-41 & 3.21 & 1.00 & 3.21 & 2.83 & 1.77 & 1.53 & 1.62 & 2.06 & 4.15 & 3.42 & 2.45 & 27.27 \\
\hline PL-A-1.1-43 & 4.14 & 1.00 & 2.81 & 2.53 & 1.60 & 1.53 & 1.52 & 2.19 & 4.39 & 3.90 & 2.43 & 28.05 \\
\hline PL-A-1.1-45 & 3.97 & 1.00 & 2.41 & 1.47 & 1.08 & 1.47 & 1.22 & 2.30 & 4.72 & 5.04 & 2.42 & 27.09 \\
\hline PL-A-1.1-47 & 3.97 & 1.00 & 1.70 & 2.62 & 2.35 & 3.04 & 2.52 & 3.76 & 6.27 & 4.89 & 3.08 & 35.20 \\
\hline$-A-1.1-48$ & 4.40 & 1.00 & 1.80 & 1.54 & 1.05 & 1.69 & 1.14 & 2.53 & 5.29 & 5.30 & 2.25 & 28.00 \\
\hline PL-A-6.5-1 & 4.14 & 1.00 & 1.60 & 2.95 & 2.59 & 2.30 & 2.67 & 2.41 & 5.79 & 2.59 & 2.04 & 30.09 \\
\hline PL-A-6.5-4* & 3.21 & 1.00 & 2.61 & 3.86 & 4.32 & 4.62 & 4.36 & 4.74 & 6.45 & 3.99 & 4.98 & 44.13 \\
\hline PL-A-6.5-6* & 3.29 & 1.00 & 2.61 & 3.79 & 3.09 & 3.81 & 2.88 & 4.42 & 6.00 & 5.04 & 4.66 & 40.58 \\
\hline PL-A-6.5-15* & 2.70 & 1.00 & 3.82 & 3.82 & 3.20 & 3.29 & 3.01 & 3.68 & 5.87 & 3.87 & 5.12 & 39.36 \\
\hline PL-A-6.5-21 & 2.02 & 1.00 & 3.61 & 4.33 & 3.30 & 3.25 & 2.87 & 3.37 & 5.96 & 3.26 & 4.50 & 37.47 \\
\hline PL-A-6.5-23* & 1.93 & 7.08 & 3.41 & 3.37 & 2.80 & 3.11 & 2.73 & 3.55 & 5.70 & 4.05 & 4.55 & 42.28 \\
\hline PL-A-6.5-29* & 3.21 & 1.00 & 2.81 & 3.73 & 4.22 & 4.17 & 4.32 & 4.43 & 5.74 & 3.92 & 4.55 & 42.09 \\
\hline PL-A-7.2-29* & 4.40 & 1.00 & 2.01 & 2.49 & 1.59 & 1.79 & 1.52 & 2.48 & 4.77 & 4.27 & 1.71 & 28.03 \\
\hline PL-A-7.2-35 & 3.55 & 1.00 & & 2.67 & 1.94 & 1.63 & 1.92 & 2.06 & 4.83 & 3.11 & 3.65 & 33.19 \\
\hline$A$ & 149,38 & 26.81 & 26.18 & 156.65 & 2.67 & 5.93 & 2.21 & 2.47 & 59.52 & 56.46 & 31.53 & 31.53 \\
\hline$\overline{\operatorname{Min}}$ & 140.00 & 17.00 & 22.06 & 99.64 & 1.31 & 4.18 & 0.49 & 1.56 & 22.38 & 9.80 & 16.00 & 16.00 \\
\hline$\overline{\operatorname{Max}}$ & 150.00 & 75.00 & 31.50 & 256.37 & 4.55 & 8.64 & 3.88 & 2.87 & 82.58 & 121.93 & 44.13 & 44.13 \\
\hline Standard deviation & 1.65 & 9.94 & 2.65 & 40.92 & 0.90 & 1.12 & 0.83 & 0.21 & 11.94 & 27.24 & 6.44 & 6.44 \\
\hline The best value limit & 151.02 & 36.76 & 28.83 & 197.57 & 3.56 & 7.05 & 3.03 & 2.68 & 71.45 & 83.70 & 37.97 & 37.97 \\
\hline
\end{tabular}

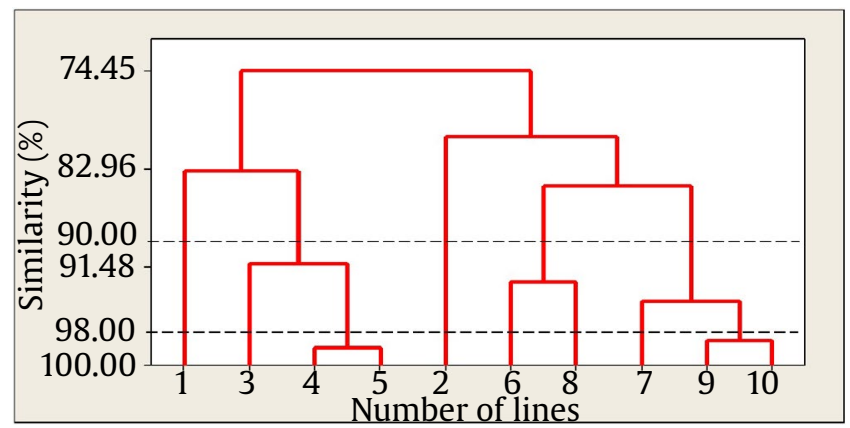

Figure 2. Dendrogram grouping of 10 selected lines of production components

\section{Discussion}

The results of this study indicated that irradiation of ion beams using Carbon and Argon ion beam can be used to improve the character of local Toraja red rice plants, particularly related to the characteristics of harvesting age, posture, and crop production. The control plants were harvested 162-166 days after seedling, while the mutant was harvested in the range of 146-161 days after seedling. Irradiation with ion beams speeds up the harvest time for 16 days or about $10 \%$ of the age of its parents. The use of Carbon
Table 4. Grouping of yield components data 10 lines selected at the planting location with a similarity rate of $90 \%$

\begin{tabular}{ll}
\hline Yield Components & Number of line \\
\hline Group I & 1 \\
Group II & $3,4,5$ \\
Group III & 2 \\
Group IV & 6,8 \\
Group V & $7,9,10$
\end{tabular}

1=PL-C-4.1-17, $\quad 2=$ PL-C-20.1-1, 3=PL-C-20.5-44, $\quad 4=$ PL-C 20.5-49, 5=PL-C-20.11-44, 6=PL-A-6.5-4, 7=PL-A-6.5-6, $8=$ PL-A-6.5-15, 9=PL-A-6.5-23, 10=PL-A-6.5-29

ion beam irradiation to produce plants with faster harvesting age was also reported by Dong and Li (2012) in sweet sorghum plants and Du et al. (2014) in Arabidopsis thaliana.

In the of the plant origin, namely in North Toraja Regency, the age of harvesting of red rice (Pare Lea) is categorized as deepest age category of 180 days after seedling (Sahardi et al. 2013). Usually it takes 21 to 30 days from seedling to planting. The long harvesting age causes low interest of the community to cultivate this type of local rice. Local Toraja rice (Pare Lea) cultivation is very limited, only to meet the needs of the use of 
these types of rice in traditional ceremonies and rituals. The presence of the Toraja local red rice variety with early maturing character is expected to increase public interest in cultivating this type of rice and prevent the extinction of this species. The production of local red rice mutants with early maturity character could be the first step to produce early maturing varieties. In this study, ion beam irradiation using Carbon ions produced 9 mutants with short postures. Unfortunately, these short characters are not present along with a short harvesting age character (early maturing) and high production yield in one individual mutant, so they are not included in the selected line group. Rice mutants with shorter postures due to ion beam irradiation were reported by Ling et al. (2013) in rice cultivars MR219. According to Ling et al. (2013), the increase in Carbon ion dosage is directly proportional to the inhibition of plant height growth.

Overall, in this study, ion beam irradiation produced 10 lines with shorter harvest ages and a high number of productive tillers. The character of the number of productive tillers is expected to be positively correlated with rice grain production. The use of ion beam irradiation to increase crop yields has been reported in various studies, including by Zhao et al. (2006) and Xie et al. (2008).

The results of the analysis and grouping of criteria on the three observation parameters, namely plant height, harvesting age and productive tillers at the planting location (Table 1) showed that Carbon irradiation treatment produced higher mutant amounts compared to Argon ion irradiation treatments, but in terms of frequency, Argon ions irradiation treatment produce higher mutant frequencies.

This shows that Carbon ion irradiation treatment is better at producing mutants mainly in terms of plant height criteria, harvesting age and number of productive tillers. Mutations that occur may be a mutagenic effect of ion beam irradiation which indicates that the treatment is quite effective in creating genetic diversity in population M2-M3. High frequency of mutations caused by irradiation of Carbon ions is caused by the energy fired by carbon ions greater that is $135 \mathrm{MeV} / \mathrm{u}$ compared to the energy in Argon ions which is only $95 \mathrm{MeV} / \mathrm{u}$ (Hayashi et al. 2007). This allows the amount of damage to the gene caused by the release of energy from the ions that are fired so that the diversity (mutants) generated is also increasing. Other advantages of ion beam mutagenesis include high survival rates, high levels of mutation induction and various other variations (Yazid and Muryono 2000).
After addition of the scores obtained from a total of 48 lines selected i.e. 27 lines from Carbon ion beam irradiation and 21 lines from Argon ion beam irradiation (Table 2), and compared with the best total score (above 37.97), 10 lines were selected with the total score above the best score (Table 3 ), namely 5 lines in Carbon treatment (PL-C-4.1-17, PL-C-20.1-1, PL-C-20.5-44, PL-C-20.5-49, and PL-C-20.11-44) and 5 in the Argon ion beam irradiation treatment (PL-A-6.54, PL-A-6.5-6, PL-A-6.5-15, PL-A-6.5-23, and PL-A-6.5 29).

The selection of character selection in the tested population is based on components that have a close relationship with the character of production. Thus, the selection of populations of diploid rice lines can use the character of the generative phase of plant height, a number of pithy grain per panicle, total grain per panicle, weight of 1,000 rice grain and character of grain yield per hill. Aryana (2007) explained the character of number of tillers, number of rice grain, total grain count per panicle, and weight of 1,000 grains can be used as character selection, whereas Safitri et al. (2011) explained the character of the number of productive tillers, number of rice grain per panicle, and the weight of 1,000 grains can be used as selection.

In Figure 2 and Table 1 above, it can be seen that at the $90 \%$ similarity level, based on the data of the production components of the 10 selected lines, 5 groups were obtained, namely Group I consisting of 1 strain, namely PL-C-4.1-17. Group II consisted of 2 subgroups consisting of 3 lines namely PL-C-20.5-44, PL-C-20.5-49, and PL-C-20.11-44. Group III consisted of 1 strain, namely PL-C-20.1-1. Group IV consists of 2 lines, namely PL-A-6.5-4 and PL-A-6.5-15. Group V consists of 2 subgroups consisting of 3 lines, namely PL-A-6.5-6, PL-A-6.5-23, and PL-A-6.5-29.

Based on the level of similarity it can be seen that the PL-C-20.5-49 and PL-C-20.11-44 and PL-A6.5-23 and PL-A-6.5-29 lines have very close kinship relationships. The line has a $95 \%$ similarity level. This shows that lines that are closely related will have a close genetic distance. This is consistent with Lee's opinion (Lee 1998), who said that closely related individuals will have a close genetic distance, whereas if they are distant relatives they will have a far genetic distance. The results of the grouping of 10 selected lines consisting of 5 groups showed that the lines in the same group generally had almost the same number of lines. Erlina et al. (2011) suggests that the same cluster is characterized by almost the same genotype name. This shows that the genotypes are formed from the same population so that the level of kinship is closer. 


\section{Conclusion}

The result of this study showed that treatments with ion beam irradiation either by using Carbon ion as well as as Argon ion are capable of producing Toraja local red rice mutant genotype with a shorter harvesting age (mid-early maturity) compared to their parent control. There is an acceleration of 1617 days or about $10 \%$ from the harvesting age of the parents. Out of 48 total selected lines, 10 lines (five of each Carbon and Argon ion beam irradiated mutants lines) meet the selection criteria of midearly maturity, high posture and many productive tillers.

\section{Acknowledgements}

We would like to thank RIKEN Nishina Center who has facilitated in terms of seed irradiation, The World Class University Fund for International Research Collaboration and Scientific Publication from Hasanuddin University which has financed (Contract No:3773/UN4.21/LK.23/2017 date on $2^{\text {nd }}$ June 2017) this research, and to, Nurhaya J. Panga, Muh. Mukhtadir Putra, Andi Muliarni Okasa and all colleagues who have helped carried out this research.

\section{References}

Abe T et al. 2012. Ion beam radiation mutagenesis. Plant Mutation Breeding and Biotechnology. Vienna Austria: CAB International and FAO. pp. 99-106.

Aryana MIGP. 2007. Phenotypic, genotypic, and crosssectional correlations and their implications for red rice selection. Journal of Crop Agro 2:1-7.

[BPPP] Badan Penelitian dan Pengembangan Pertanian. 2003. Agricultural Research and Development Agency. Guide to Rice Plant Characterization and Evaluation System. National Germplasm Commission. Agriculture department.

Dong XC, Li WJ. 2012. Biological features of an early-maturity mutant of sweet sorghum induced by carbon ions irradiation and its genetic polymorphism. Adv Space Res 50:496-501. DOI:/10.1016/j.asr.2012.04.028
Du Y et al. 2014. Mutagenic effects of carbon-ion irradiation on dry Arabidopsis thaliana seeds. Mutat Res 759:2836. DOI:10.1016/j.mrgentox.2013.07.018

Erlina D et al. 2011. Genetic characterization of sorgum (Sorghum bicolor L. Moench) germplasm collection based on SSR markers. Jurnal Litbang Pertanian 25:1-15.

Hayashi Y et al. 2007. Effects of ion beam irradiation on mutation induction in rice. Cyclotrons and Their Applications Eighteenth International Conference. pp. 237-239.

Lee M. 1998. DNA markers for detecting genetic relationship among germplasm revealed for establishing heterotic groups. Presented at The Maize training Course, CIMMYT, Texcoco, Mexico.

Ling QF et al. 2013. Relationship between plant growth and cytological effect in root apical meristem after exposure of wheat dry seeds to carbon ion beams. Nucl Insrum Meth B 305:9-15. DOI:10.1016/j.nimb.2013.04.046

Riadi M et al. 2019. Local rice genotypes of Tana Toraja and North Toraja Regencies: kinship relations and character interaction. IOP ConfSer:Earth Environ Sci 270:012039. DOI:10.1088/1755-1315/270/1/012039

Safitri Het al. 2011. Evaluation of agronomic character and yield components of 35 double haploid rice genotypes from Antera Culture. In: Seminar on Scientific Proceedings of the National Rice Research Results, November 2425, 2010. Book 1. ICRR-Agricultural Research and Development Agency. pp. 87-97.

Sjahril R et al. 2018. Effect of heavy ion beam irradiation on germination of local Toraja rice seed (M1-M2) mutant generation. IOP ConfSer:Earth Environ Sci 157:012046. DOI:10.1088/1755-1315/157/1/012046

Suhardi et al. 2013. Diversity of morphological character of local rice ground in upland Toraja Land South Sulawesi. In: Proceedings of the National Seminar on Genetic Resources of Agriculture. Bogor: Publication Repository Badan Litbang Pertanian. pp. 134-143.

Wahdah R et al. 2012. Diversity of character of local varieties of South Kalimantan.Journal of Agricultural Food Research 31:158-165.

Xie ZK et al. 2008. Study of mutation breeding with heavy ion irradiation on potatoes. Nuclear Physics Review 25:187-190.

Yazid M, Muryono H. 2000. Study on the characterization of accelerators for applications in the field of biotechnology. Proceedings of National Seminar on Accelerator Technology and Its Application 2:139-147.

Zhao LZ et al. 2006. Preliminary study on selection new variety of spring wheat by irradiation of heavy ions. Acta Agric Boreali-Occident Sin 15:17-19. 